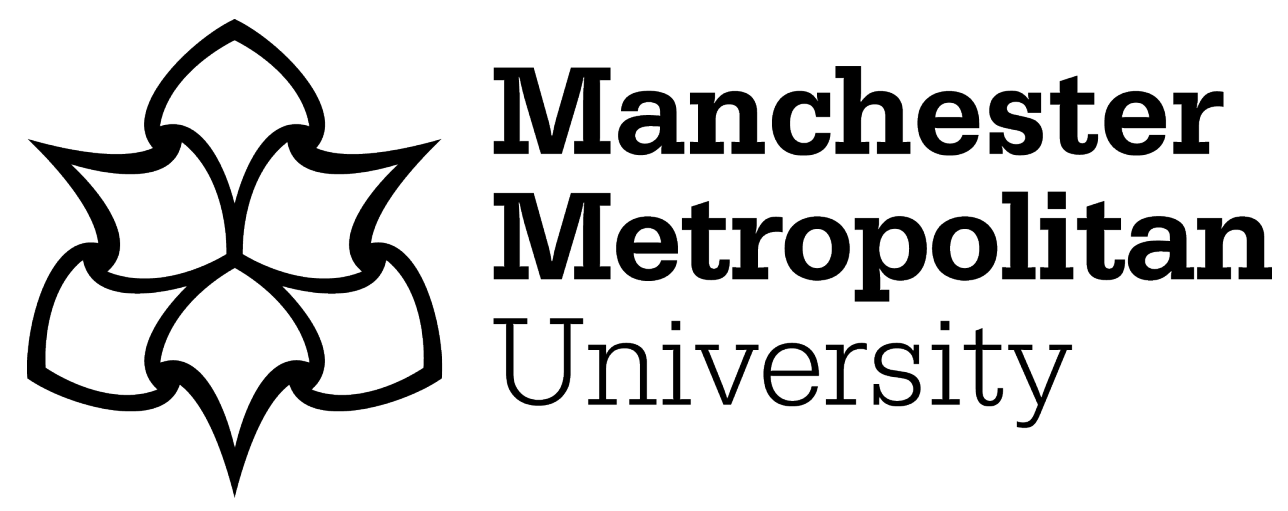

van Grinsven, B, Betlem, K, Cleij, TJ, Banks, CE and Peeters, M (2016) Evaluating the potential of thermal read-out techniques combined with molecularly imprinted polymers for the sensing of low-weight organic molecules. Journal of Molecular Recognition, 30 (1). ISSN 1099-1352

Downloaded from: https://e-space.mmu.ac.uk/617104/

Publisher: Wiley

DOI: https://doi.org/10.1002/jmr.2563

Please cite the published version 


\title{
Evaluating the potential of thermal read-out techniques combined with Molecularly Imprinted Polymers (MIPs) for the sensing of low-weight organic molecules
}

\author{
B. van Grinsven ${ }^{1}$, K. Betlem ${ }^{2}$, T.J.Cleij ${ }^{1}$ C.E. Banks ${ }^{2}$, M. Peeters ${ }^{2, *}$ (corresponding author) \\ 1. Maastricht Science Programme, Maastricht University, P.O. Box 616, 6200 MD Maastricht, The \\ Netherlands.
}

2. Faculty of Science and Engineering, School of Science and the Environment, Division of Chemistry and Environmental Science, Manchester Metropolitan University, Chester Street, Manchester M1 5GD, United Kingdom.

In recent years, there has been a tremendous increase in the papers published on synthetic recognition elements. Molecularly Imprinted Polymers (MIPs), also referred to as 'man-made mimics' of antibodies, are able to rebind their template molecules with high affinity. Advantages compared to natural receptors include their excellent thermal and chemical stability, low-cost, and ease of the production process. However, their use in commercial biosensors is limited due to the difficulty to incorporate MIPs into suitable sensing platforms and traditional detection techniques, such as chromatography, that require bulky and sophisticated equipment. In this review, we evaluate the potential to use MIPs combined with thermal read-out for the detection of low-weight organic molecules. We discuss thermal methods to study MIP-template complexation and to determine neurotransmitters concentrations. In particular, we highlight the heat-transfer method (HTM), a recent technique that is straightforward, low-cost, and requires minimal instrumentation. Until now, sample preparation involves a two-step process, making it time-consuming, and measuring biological samples is difficult due to the noise in the signal. Different sample preparation methods are discussed and it will be demonstrated how this affects the thermal response. An outlook is given in novel methods that can simplify and speed up sample preparation. Finally, we show a novel thermal technique, which is based on the analysis of transport of thermal waves rather than evaluating the fixed heat-transfer resistance. Through applying the concept of thermal waves, signal-to-noise ratio is significantly increased, which will result in lower detection limits and has a high potential for the study of biological samples.

Corresponding author: Dr. Marloes Peeters (m.peeters:mmu.ac.uk)

Manchester Metropolitan University, Chester Street, M15GD, United Kingdom.

Keywords: Molecularly Imprinted Polymers (MIPs), biomimetic sensors, neurotransmitters, thermal detection, heat-transfer. 


\section{Introduction}

\subsection{General Introduction on MIPS}

Molecularly Imprinted Polymers are polymers containing nanocavities with a pre-determined selectivity towards their template molecules [1],[2]. They are sometimes referred to as 'man-made mimics of antibodies', but compared to natural antibodies their advantages include: low-cost [3], robustness [4], and stability under extremes of $\mathrm{pH}$ and temperature [5]. The molecular imprinting technique dates back to the 1930's, when Polyakov concluded that the selectivity of silica matrices for a certain template depended on the chemical nature of the additive that was introduced during the synthesis [6]. Even though several papers were published on this topic in the 1930's, the start of the current molecular imprinting technique technology did not emerge until the 70's when the groups of Wulff [7] and Klotz [8] independently reported on organic polymers with pre-determined ligand specificity. When the Mosbach group first introduced the concept of non-covalent binding [9], it was a real breakthrough in the field as this allowed easy extraction of the template from the matrix. As a result, while from the first paper of Polyakov in 1931 until 2006 a number of 1450 MIP-based articles was documented [10], in the period from 2004 to 2011 alone an exponential increase was seen with 3779 references MIP-related articles $[10,11]$. Over the past years this number is steadily increasing, with the focus shifting from development of solid materials and monolayers for chromatography towards biosensor based applications [12],[13]. The first chemical sensor arrays were developed by groups of Dickert [14],[15], Shimizu [16],[17] and Takeuchi [18],[19]. The use of MIPs for sensing applications remains challenging, current problems include the development of a suitable interface layer $[1,20]$, leaching of trapped template [21, 22], and the lack of straight-forward and low-cost read-out techniques[23, 24]. However, with current methods it is possible to compete with enzymes, as was demonstrated by Chianella et al.[25]. The group of Piletsky has developed a straightforward approach to coat microplate wells with nanosized MIPs (Figure 1). 


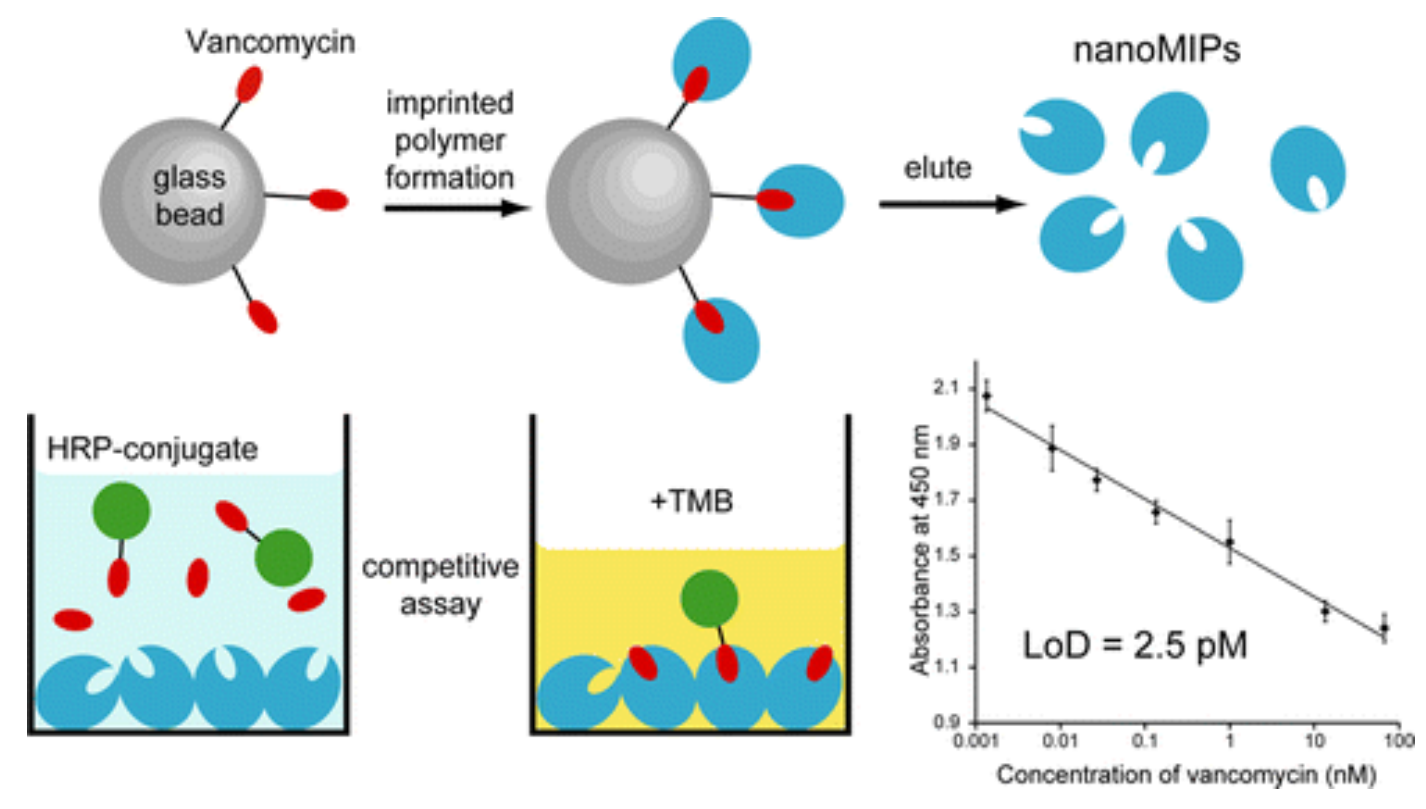

Figure 1. NanoMIPs were synthesized with a solid approach with vancomycin as the template. With a horseradish peroxidase-vancomycin conjugate, detection limits in the order of $2.5 \mathrm{pM}$ were achieved in buffer and in blood plasma[25]. Reproduced with permission from ref 25. Copyright 2013, American Chemical Society.

The specificity of the nanoMIPs towards vancomycin was tested with a competitive assay as follows. First, well plates were coated by addition of nanoMIPs solutions, which were evaporated overnight. To prevent non-specific binding, the wells were blocked by incubating them with bovine serum albumin (BSA) solutions in PBS. Finally, solution of horseradish peroxidase (HRP) and free vancomycin were added. The concentration was then calculated by using the absorbance values at $450 \mathrm{~nm}$ and comparing this to the calibration curve. To test the cross-reactivity, the same competitive assay was performed with three other commonly used antibiotics, respectively, gentamicin, bleomycin, and amoxicillin.

This approach is a promising alternative to traditional ELISA assays as the sensitivity of the described assay is a factor of three orders of magnitude better. In addition, MIPs can be stored for a long period of time without adverse effect to the binding properties and non-specific binding in biological samples is minimal [26],[27]. In the case of the nanoMIP assay for vancomycin, well plates MIPs could be stored 1 month at room temperature before adverse effects on the detection of the template were observed [25]. The approach is not just limited to vancomycin, in the past the same assay has been reported for beta-agonists such as norepinephrine and epinephrine. With the generic nature of the nanoMIP preparation in mind, this suggest the assays for more analytes, such as pollutants, peptides, proteins and disease markers, can be developed in a relatively short time. In 2015, MIP Diagnostics Ltd. was founded, a spin-off from the University of Leicester, who have developed an automated device for synthesizing MIPs within several weeks of receiving the target. 
For biosensing purposes, most MIP-based biosensing platforms are focused around optical, fluorescent or electrochemical detection. In this review, we focus on the application of thermal readout techniques for the detection of small organic molecules with MIP-based sensor platforms. First, we discuss the use of ultrasensitive isothermal calorimetry, which generates thermodynamic data and measures template-MIP binding in solution by evaluating the binding enthalpy. In the next section, thermal techniques for binding of organic small molecules to immobilized MIP-layers are reported; including thermistors and the heat-transfer method. Finally, an outlook is provided on a new thermal technique that relies on the thermal wave transport analysis.

\subsection{Comparison of thermal detection techniques}

We will briefly introduce four different thermal techniques here and describe their similarities and differences. Examples of small molecule detection with the methods will be discussed in more detail in section 2, 3, 4 and 5.

Isothermal titration calorimetry is the only method in which the MIPs do not need to be immobilized on the surface. To perform measurements, the template is dissolved in a buffer solution into which aliquots of either the monomer or the polymer microgel are titrated [28]. Changes in the heat (W) are recorded and can be correlated to the fraction of bound ligand. It is used to determine binding affinities $\left(\mathrm{K}_{\mathrm{a}}\right)$ and study thermodynamic parameters, such as the binding enthalpy $(\Delta \mathrm{H})$, entropy changes $(\Delta \mathrm{S})$ and binding stoichiometry or complexation ratio[29]. This makes this technique perfectly suitable for high-throughput screening of monomers, but it is not commonly used for detection.

The second method is based on thermistors; a type of resistor, in general a polymer or a ceramic, whose resistance is highly dependent on the temperature. A typical sensor would involve MIP particles packed into columns (Scheme 1) and subsequently placed into insulated thermistor blocks. To perform measurements, analyte solutions are introduced into the system and temperature differences are monitored [30]. 


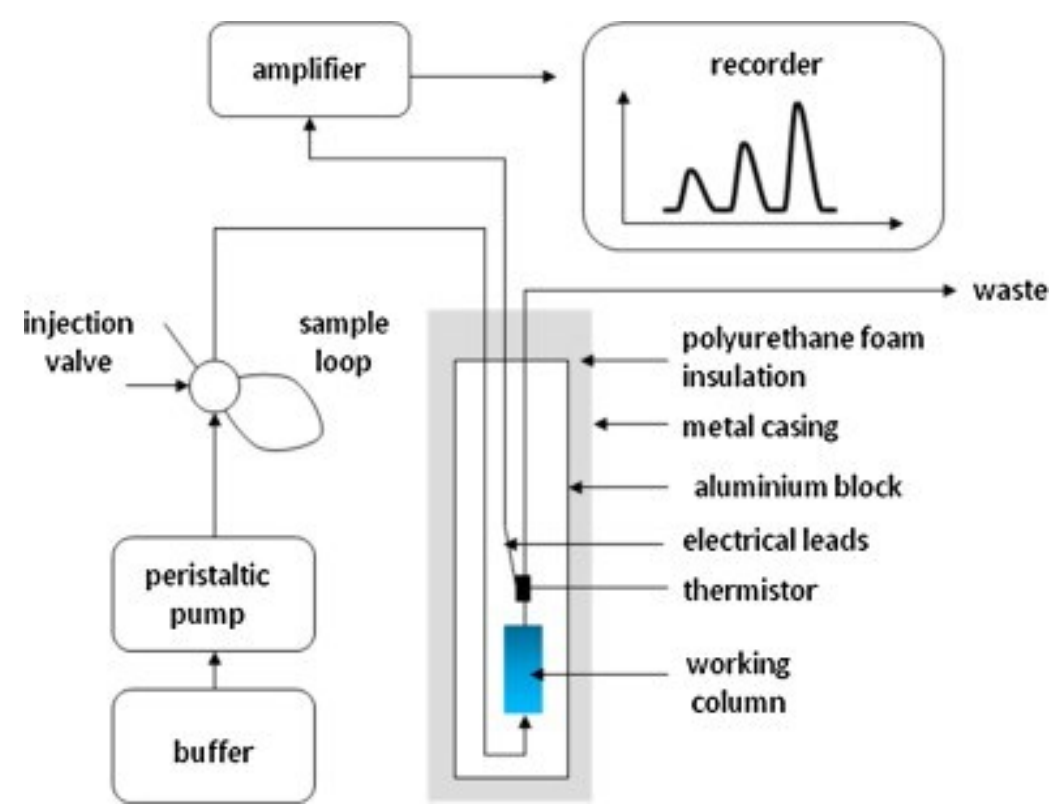

Scheme 1. At the top of the column packed with MIP particles, a thermistor is fixated that is connected to a Wheatstone bridge to determine temperature changes of $0.001^{\circ} \mathrm{C}$. Reproduced with permission from ref 30, copyright 2013 from Elsevier.

A temperature profile is measured over time and binding of substrates to the MIP layer results in changes in the $\mathrm{mK}$ range. The temperature peak height, in addition to area under the curve, is proportional to the enthalpy and corresponds to a specific substrate concentration. For most reactions, concentrations can be determined in the 0.01-100 $\mathrm{mM}$ range [31].

The heat-transfer method is significantly different to these other methods; instead of measuring a temperature, a temperature gradient is obtained by applying a heat-flow through the MIP particles. The thermal resistance is then determined by dividing the gradient over the power into account, which is then correlated to the concentration of target molecules bound to the MIP layer [32]. Measurements are performed with a low-cost and home-made set up, while the other two thermal detection methods require expensive equipment. The main advantage is the limit of detection, with HTM this is in the $\mathrm{nM}$ range compared to $\mathrm{mM}$ concentrations measured by thermistors. However, this method is not suitable to perform kinetic measurements and no additional information about the thermodynamics parameters $\Delta \mathrm{H}$ or $\Delta \mathrm{S}$ is obtained [32].

Finally, thermal wave transport analysis is described, a novel method that has only been used for the determination of dopamine concentrations [33]. Experiments were performed with the same set up as for HTM. Instead of keeping electrodes functionalized with MIPs at a fixed temperature, a thermal wave is sent through the MIP sample by first heating it up and subsequently cooling it down. The element that is measured is not the thermal resistance but the phase shift, as this is associated with how fast or how slow a system responds when it is subjected to temperature changes. It has to be noted that increases in the thermal resistance, which occur due to binding of small organic molecules 
to the MIP layer, will also result in a delay in the phase shift. Advantages include that this two methods can be applied simultaneously, but advantages of TWTA are a shorter measurement time and higher effect size due to decrease of the noise on the signal.

This information is summarized into Table 1 to demonstrate the strength and weaknesses of each technique.

\subsection{Advantages thermal detection for biosensing of small organic molecules}

Biosensors with MIPs as recognition element instead of natural receptors offer several advantages, including; long-term storage, excellent stability, re-usability, possibility to tailor the MIP to its target, and animal use is not required [3,11]. The area of MIPs for separation and extraction is wellestablished and chromatography is commonly used to determine target concentrations. MIP particles are directly packed into columns and can distinguish between targets and their corresponding enantiomers. The main drawbacks are the cost of the equipment and the fact that it is not possible to develop a portable sensor, which can measure concentrations on the spot. Miniaturization is important when designing a point-of-care sensor, and optical and gravimetric techniques do not offer a viable alternative. Electrochemical sensors can be operated as handheld devices, are suitable to determine traces of molecules, and are relatively low-cost[20]. However, issues can arrive with the selectivity, interpretation of the data, and it is often limited to the use of monomers or a template that possesses electroactive properties.

All discussed thermal detection techniques have the advantages that they are simple, easy to interpret, and can be applied to all templates and versatile MIP polymer structures. ITC and thermistors provide valuable information for the screening of monomers and thermodynamic parameters that are difficult to obtain with other methods. The other two methods, respectively, HTM and TWTA, have the possibility of integration into portable on-site sensors. The acquired limits of detection are suitable for detection in buffer solutions, but more research needs to be performed to demonstrate their proofof-application with relevant biological samples.

\section{The use of calorimetry for MIP template complexation and recognition}

In order to use molecular imprinting technology for commercial applications, there needs to be a high affinity between the developed MIP and its template. In previous experimental studies, techniques that were used to study the template/functional monomer interaction include Nuclear Magnetic Resonance (NMR) studies [34],[35], FTIR spectroscopy [36], [37], and to a lesser extent, calorimetry [38]. 
With calorimetry, the release and absorbance of reaction heat is measured during physical state changes of a material by heating $[39,40]$. It offers the advantage that no immobilization of the MIPs or any modification to starting reactants is required, but the equipment is not generally available in labs in contrast to FTIR and NMR, thereby limiting its application. Studies on the pre-polymerization complex have been performed with two calorimetric methods; respectively, isothermal batch and titration calorimetry. The latter is preferred, since in batch calorimetric experiments unstirred samples are affected by strong solvent-polymer interactions, such as swelling of the material over time.

Nicholls has determined that the degree of template complexation is associated with the change in Gibbs free energy of formation of each mode of template-functional monomer interaction [29]. It is assumed that MIPs do not undergo conformation changes during recognition of the template and hydrophobic interactions are negligible since rebinding experiments are in general performed in lipophilic solvents. This means that the energetic contributions of template-functional monomer interactions, according to Nicholls, can be simplified to[41] :

Equation 1:

$$
\Delta G_{\text {bind }}=\Delta G_{t+r}+\Delta G_{r}+\Delta G_{v i b}+\Sigma \Delta G_{p}
$$

where the Gibbs free energy changes are: $\Delta G_{\mathrm{bind}}$, complex formation; $\Delta G_{\mathrm{t}+\mathrm{r}}$, translational and rotational; $\Delta G_{\mathrm{r}}$, restriction of rotors upon complexation; $\Delta G_{\mathrm{vib}}$, residual soft vibrational modes; $\Sigma \Delta G_{\mathrm{p}}$, the sum of interacting polar group contributions.

There are several examples in literature of the use of ultrasensitive isothermal titration calorimetry to evaluate the binding properties of MIPs towards it template. Weber et al., [28] studied the response of microgels imprinted with L-Boc-phenylalanine anilide (L-BFA) to a range of probe molecules, observing significant difference between the binding enthalpy of the original template compared to the other competitors. Hsu et al. [42] determined that insertion of a styrene monomer into a MIP composed of polyethylene glycol dimethacrylate enhanced the extraction of the enzyme Ribonoclease A. This was determined via two different detection methods, respectively, with Enzyme-Linked ImmunoSorbent Assay (ELISA) tests and with microcalorimetry. The results are summarized in Table 2, where the number after SM indicates the percentage of styrene incorporated into the monomer mixture.

From this table, it can be seen that the imprint factor (IF) as calculated by ELISA assays and microcalorimetry follows roughly the same trend. The results for SM-40 are significantly different however, where ELISA assays predict a lower IF (1.53) with microcalorimetry a significant increase 
(4.96) is determined. This could be because in the case of ELISA tests MIPs are functionalized onto a surface and non-specific binding becomes a more important factor.

Overall, isothermal calorimetry allows fast and low-cost screening of template-monomer interactions and is used for the design and optimization of MIPs for a variety of targets. Selectivity can be determined up to a level of chiral recognition, as was demonstrated with a MIP for phenyl- $\alpha$ mannopyranoside [43]. At a low degree of occupation of the binding sites, significant differences were observed in the endothermic heat effect for the $\mathrm{D}$ and $\mathrm{L}$ enantiomers, indicating enantioselective rebinding of the template. Besides detection, microcalorimetry is also used to evaluate binding mechanisms, complexation ratios and material properties of MIPs. The binding mechanism of 2-4dichlorophenoxyacetic acid to a vinylpyridine MIP was elucidated by microcalorimetry [44]. It occurs in several distinct steps, starting with the dehydration of the pores, followed by binding of the template, and finally, rearrangement of water molecules. The process was $\mathrm{pH}$ dependent, as shown in Table 3 where the thermodynamic parameters for the MIP and NIP are listed at different $\mathrm{pH}$ values. The values obtained in this study are comparable to previous literature [45]. It shows that at acidic $\mathrm{pH}$ values, binding to the MIP is driven by entropy while for the NIP enthalpy is the dominating force. This is line with the proposed binding mechanism, which involves steric complementary. At basic $\mathrm{pH}$ values the electrostatic repulsion forces control the binding and a higher positive enthalpy is obtained [44]. The use of isothermal titration calorimetry to monitor the energetics of formation of the MIP pre-polymerization complex was demonstrated by Zhao et al. [46]. A MIP for patulin, a contaminant, was prepared by grafting polymer brushes onto a silica support. The formation of the pre-polymerization complex was determined by titrating solutions of the functional monomer, acrylamide, to template solutions in the calorimetric cell. By measuring the heat changes after each addition the binding constant $(\mathrm{K})$ and enthalpy change $(\Delta \mathrm{H})$ were calculated. 
Time (min)

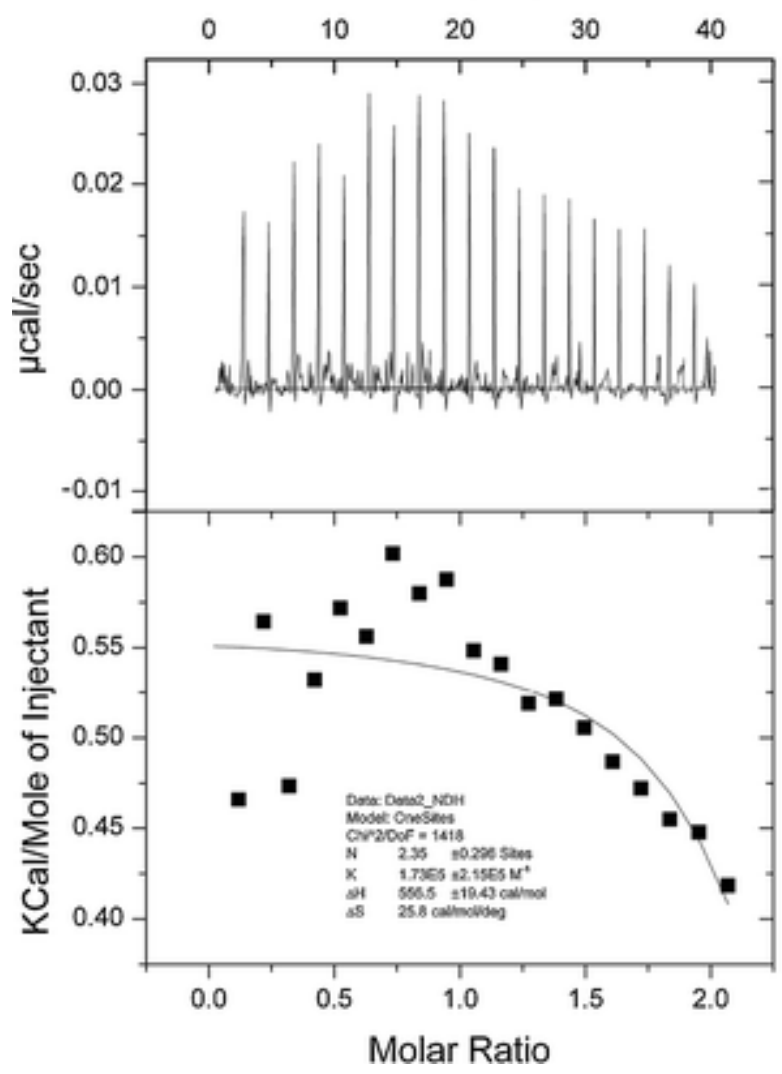

Time (min)

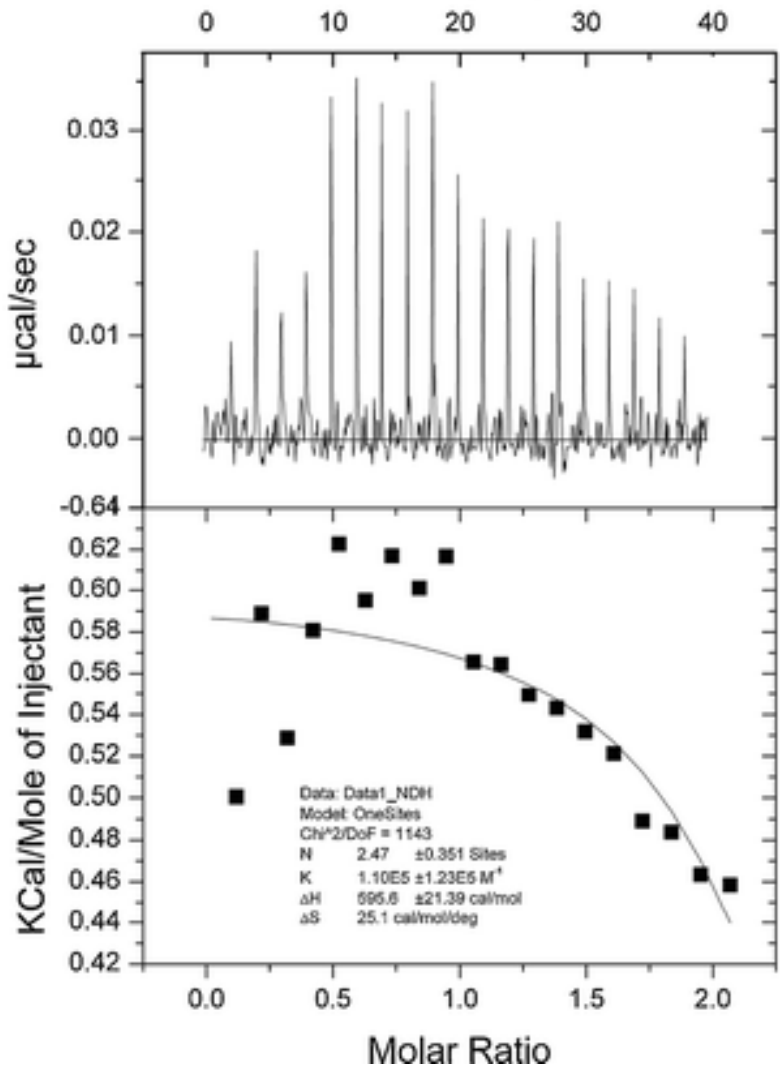

Figure 2. Isothermal titration calorimetry data for the template binding to the functional monomer acrylamide. The profiles are given of titration of acrylamide with patulin (left) and 6-hydroxynicotinic acid (right) in aqueous solutions. In the upper panel the raw data of the titration is provided, with in the lower panels the normalized data is provided[46]. Reproduced with permission from ref 46, copyright 2011 from Springer.

From the microcalorimetry graphs, it was determined that there is a strong donor-acceptor hydrogen bond formed between the monomer and both templates. The plot of the kcal/mole of the injectant vs the molar ratio demonstrates the affinity distribution and the maximum peak height at a molar ratio of 1 indicates that there is a 1:1 ratio of binding for the monomer to the template. This was confirmed by molecular modeling, and by performing batch rebinding experiments and analyzing them with Scatchard analysis. While for these two templates a similar pattern in titration experiments is observed, for a similar molecule, 5-hydroxymethyl-2-furaldehyde, a distinctly different result is obtained. As a consequence, the synthesis needs to be adapted and after identifying the groups participating in pre-polymerization complex formation need to be matched with the functional monomer that is employed in the MIP synthesis.

Fish et al.[47] used isothermal titration calorimetry to study complexation ratios between the functional monomer, methacrylic acid, and the template, the drug cinchonidine. Calorimetric titrations elucidated that the minimum energy of the complex was at a ratio of $4: 1 \mathrm{~mol} / \mathrm{mol}$ for the 
monomer relative to the template. This demonstrates that isothermal calorimetry is a useful tool for the synthesis of MIPs, as it speeds up the optimization process and allows for screening of different monomers. It can also be used to model the presence of heterogeneous binding sites in MIPs [48, 49], which supports in the design process[50].

\section{Thermistors as read-out technique for biosensing with MIPs}

Thermistors are resistors that exhibit a large and precise change in electrical resistance when subjected to a temperature change [31]. Biochemical processes involve the evolution of heat, with the total heat that is produced depending on the molar enthalpy change $(\Delta \mathrm{H})$ and the total number of moles of product (n) used in the reaction [30], [51]. The relative temperature change associated with the reaction is dependent on the total heat capacity $\left(\mathrm{C}_{\mathrm{s}}\right)$ of the system. This difference $\Delta \mathrm{T}$, as is measured with the read-out of the sensor, is then defined by Equation 2 [30].

Equation 2:

$$
\Delta T=-\left(\mathrm{n} \Delta \mathrm{H} / \mathrm{C}_{\mathrm{s}}\right)
$$

Enthalpy changes for enzyme catalysis are associated with values up to $200 \mathrm{~kJ} / \mathrm{mol}$, which is sufficient to determine metabolites concentrations up to the low micromolar regime [52, 53]. In molecular imprinting, as described previously, binding of the template to the nanocavities results in an enthalpy change. The benefit of this technique is that it is label-free and the MIPs used in analysis do not need to be integrated on the sensor, eliminating the need of an immobilization step.

Nowadays, they are used for several sensing applications, but examples of MIP-based platforms with thermistors as read-out are sparse. The first combination of a thermistor transducer for the recognition of small organic molecules with catalytically active MIPs was described by Lettau et al. [54]. In this work, MIPs were prepared that possessed catalytic activity towards the substrates phenylacetate and 4-nitrophenylacetate. For functionalization of the particles, $150 \mathrm{mg}$ of MIP or NIP were packed in a column in a flow reactor. Phenylacetate concentrations in aqueous solutions $(0.5-5 \mathrm{mM})$ were introduced to the system, leading to a peak in the temperature due to conversion of the substrate. After flowing the system with buffer, a negative peak was observed that returned to the baseline, which was because the substrate was removed from the reactor. Saturation occurred from concentrations higher than $0.5 \mathrm{mM}$, with the operating regime of the sensor from 0.05 to $0.5 \mathrm{mM}$. The specificity of the MIPs was demonstrated by the addition of the reaction products phenol and acetic acid, which gave a significantly different response in the calorimetric signal. The data was then used to determine kinetic parameters of the MIPs and a Michaelis Menten constant of $2.2 \mathrm{mM}$ was calculated, which is similar to what was previously determined for esterolytic MIPs. 
In a follow up on this work, a MIP for nitrofurantoin was optimized by combining diaminopyridine derivative (BMP) as the first monomer with a urea based derivative (VFU) as the second monomer. For the first time, detection with a MIP-based thermistor was achieved in an organic solvent[55] [56]. The binding of the template to the MIP is observed as an exothermic peak signal that appears after injection of the analyte, which is subsequently followed by endothermic desorption after washing with the solvent. This exothermic peak correlates to enthalpy changes associated with non-covalent complex formation and changes of solvation of the template at the imprinted polymer[43, 57]. By monitoring the exothermic peaks, it was possible to measure nitrofurantoin in the micromolar regime in a combination of acetonitrile and dimethylsulfoxide (DMSO). In Figure 3, the binding of the template nitrofurantoin is given at the exothermic peak for both the MIP and the reference NIP [56].

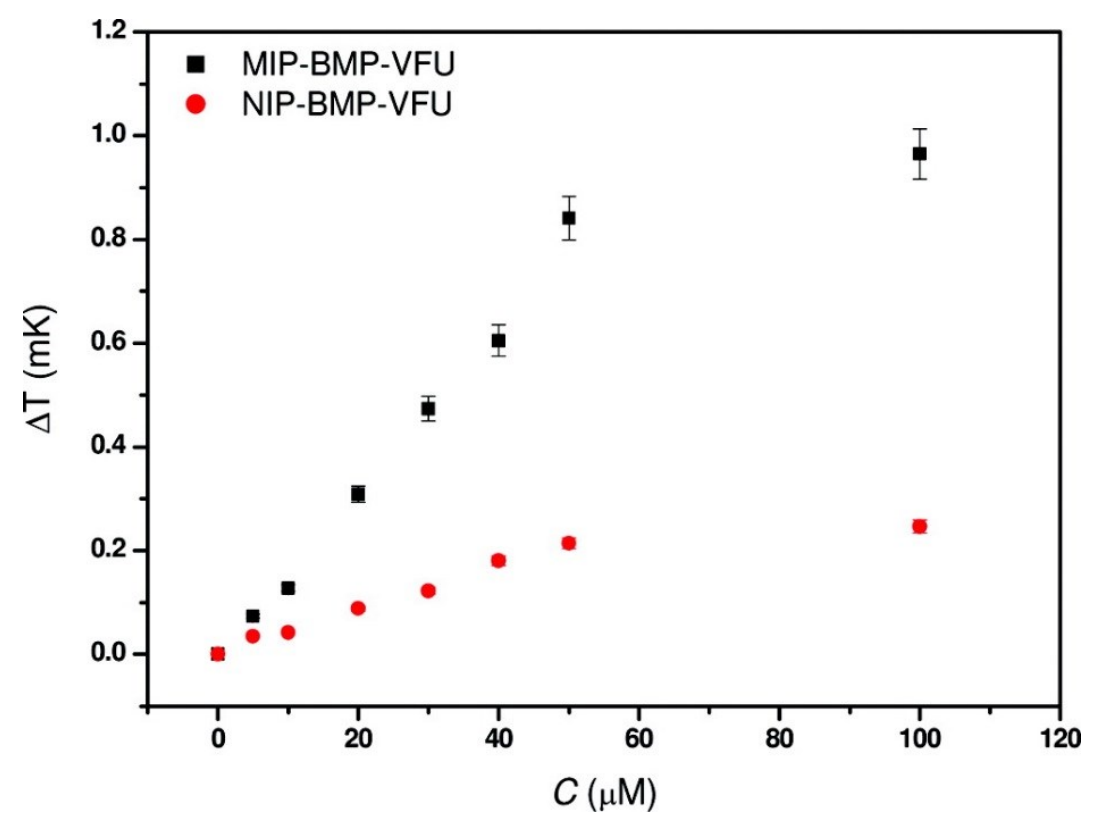

Figure 3. Concentration dependence of nitrufurantoin binding to the imprinted polymer based on two functional monomers MIP-BMP-VFU and the control polymer NIP-BMP-VFU investigated by thermometric sensing in acetonitrile $+0.2 \%$ DMSO. (Data represent mean ( s.d., $n=3$ ).

Reproduced with permission from ref 56, copyright from Analytical Chemistry.

The imprint factor that was achieved with thermal detection was similar compared to traditional batch rebinding experiments. There are examples in literature which show significant improvement in the imprint factor such as MIPs containing phenyl boronic acid residues for the rebinding of fructosyl valine[58]. In contrast to previous experiments, here a flow through setup was used to enhance the sensor performance. This concept was extended to fructose and pinacol and showed that the choice of the cross-linkers has a significant impact on the non-specific binding to the control polymer [59]. 
With this method, label-free detection of fructose was achieved in the range of $0.5-10 \mathrm{mM}$ in buffer solutions and the imprint factor was increased with a factor or nearly tenfold compared to traditional batch rebinding experiments. An additional benefit of combining MIPs with thermistors is that it can be used for characterization of the material since differences in heat generation reflect different recognition sites present in the MIPs [54].

\section{The Heat-Transfer Method (HTM)}

In 2012, van Grinsven et al. [32] discovered an anomaly in the thermal behavior of DNA at its melting temperature. At this temperature, DNA undergoes a structural conformation from a well-defined elongated brush to a spaghetti-coiled structure, increasing the surface area by nearly $150 \%$. This effect is known to result in an increase of the electrical resistance due to the formation of an additional insulating layer [60], but the increase in the thermal resistance $\left(\mathrm{R}_{\mathrm{th}}\right)$ had not been reported in literature before. The thermal resistance is analogous to the electrical resistance and is defined according to Equation 3 [61].

Equation 3: $R_{t h}=\frac{\Delta T}{P}$

In this formula, $\Delta \mathrm{T}\left({ }^{\circ} \mathrm{C}\right)$ corresponds to the temperature difference over the sample and $\mathrm{P}(\mathrm{W})$ to the heating power of the heat sink. The schematic design of this heat-transfer device is shown in Figure 4.

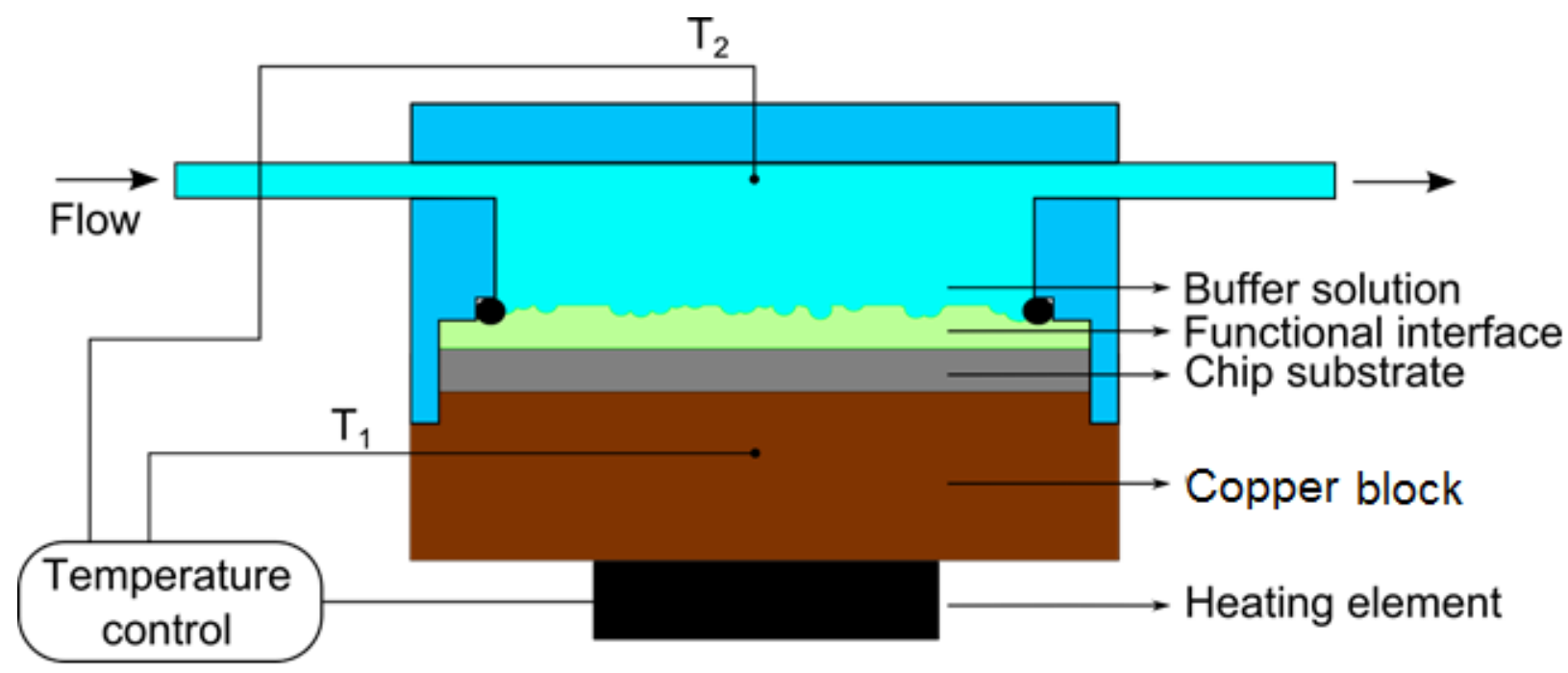

Figure 4. Schematic layout of the HTM setup, in which the sensor chip is connected to a copper block with the functional interface facing the liquid flow cell. The temperature $T_{1}$ is actively steered, while temperature $T_{2}$ in the fluid is recorded with a second thermocouple. With the heat- 
transfer related parameters $\mathrm{T}_{1}-\mathrm{T}_{2}$ and the input power $\mathrm{P}$, the thermal resistance in time at the solid liquid-interface is calculated. Reproduced with permission from ref 61. Copyright 2012, American Chemical Society.

This technique, referred to as the heat-transfer method (HTM), has been extended to a variety of biosensing applications since it is label-free, low-cost, fast, sensitive, and user-friendly due to the nature of the proposed read-out technology. At the moment, current use is for determining phase transitions in lipid vesicles [62], single nucleotide polymorphisms in DNA[32], measuring proteins concentrations by aptamers[63] [64], and molecular imprinting technology [65, 66]. In the latter, we can distinguish between the surface imprinting technique that is used for larger templates such as cells and proteins[67, 68], and the bulk imprinting technique, which is more common for small organic molecules [2, 69]. For surface imprinting, cells are pressed onto a semi-cured polyurethane layer and subsequently removed after cross-linking [66]. This removal results into the presence of micron-sized cavities on the surface and when template cells rebind, heat-transfer is blocked into that direction. With HTM as read-out technique, specific detection of cells with SIPs with a limit of up to $10^{\wedge} 4$ cells $/ \mathrm{ml}$ was achieved. In follow up of this research the detection limit was improved by a factor of $30 \%$ by using polished alumina substrates, eliminating the use of conductive silver paste and thereby lowering the resistance at the interface [70]. This principle is not just limited to detection, but has also been used for screening of cell quality assays and demonstrated that after culturing cells for a prolonged period of time, the bond to the imprint is weaker due to the difference in functional groups on the membrane [71]. Selectivity problems can be overcome by coupling the system to a peristaltic pump in order to control the flow-rate during sample addition. The competitor molecules bind with a lower affinity to the MIP cavities on the surface and were easily removed after flushing at a high rate with a buffer solution. This shows that non-specific binding to the imprints is completely overcome by shear forces imposed by the liquid flow. In past work, it was demonstrated this is sufficient to prevent binding of different types of breast cancer cell lines.

In the case of bulk imprinting, the cavities are not present on the surface but inside the material and rebinding of the template results into partial blocking of the heat-transfer inside the pores. The underlying principle detection principle by HTM is referred to as the "pore-blocking model" [65], shown in Figure 5. 

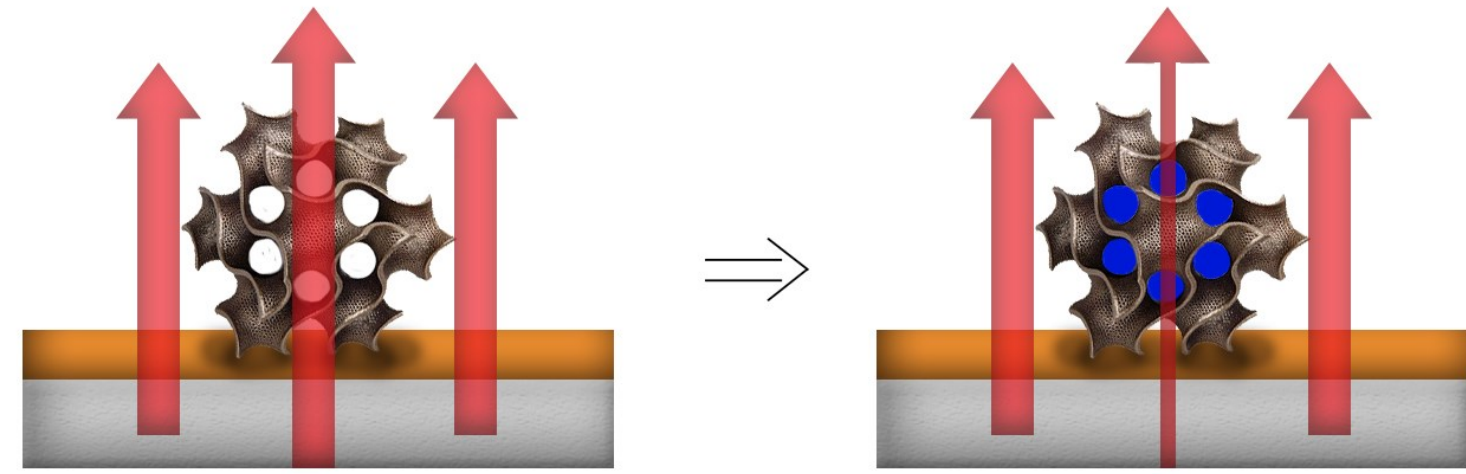

Figure 5. Artistic impression of the "pore-blocking model", with the MIP particle embedded in the surface with various pores or binding sites of the template molecule. When the channels are filled by the target molecule (indicated by blue dots), heat-flux through the MIP layer is strongly reduced and the overall heat-transfer resistance is increased. Reprinted with permission from ref 65 .

Copyright Bioanalytical and Analytical Chemistry, 2013.

To functionalize the MIP particles on the surface, the particles are applied onto an adhesive layer that was spin-coated prior on the electrode. Several polymers were tested as adhesive layers, including polyvinylchloride (PVC) and modified MDMO-PolyPhenyleneVinylene (MDMO-PPV). Both materials have a low glass transition temperature and by slight heating of the substrate, the polymer coating will exhibit liquid-like properties and MIP particles are allowed to sink into the adhesive layer. The main difference is that PVC is insulating compared to MDMO-PPV, and for performing heat-transfer measurement it was preferred to have a conductive adhesive layer on the substrate in order for heat to freely pass through the electrode surface. After functionalizing the MIPs onto the electrodes, attachment was studied with optical microscopy and it was determined that $\sim 30 \%$ of the surface was occupied with MIP particles [65].

This process has been performed for MIPs designed for neurotransmitters histamine, L-nicotine, and serotonin, and detection limits between 50 to $100 \mathrm{nM}$ were achieved in buffered saline solutions using HTM as read-out technique. As references, the NIPs were used and the response of the MIPs was tested against competitor molecules. For L-nicotine its metabolite cotinine was studied, for the template serotonin dopamine was employed, and histamine was tested against histidine. As a first proof-of-application, saliva samples spiked with L-nicotine were measured. This was proven to be difficult, since high noise levels were obtained that originate from the viscosity of the sample and from the noise generated by the power supply [65]. By fine tuning the settings of the feedback loop, 
the detection limit of the neurotransmitter L-nicotine was brought down to $33 \mathrm{nM}$ in buffer solutions [72].

A first array sensor set up of the HTM equipment was developed by Wackers et al., [73], who segmented a flow-through sensor into four quadrants with a sample volume of $\sim 20 \mu \mathrm{L}$. With this design, it was possible to discriminate between histamine, serotonin and L-nicotine without significant cross-selectivity. To enhance the detection limit with HTM as read-out, improvements can be done on the heat-transfer of the whole system, which includes both the MIPs and the supporting electrode, and on the functionalization of the synthetic receptors on the surface. The MIPs itself are insulating, therefore thinner layers rather than micron-sized particles would lower the overall thermal resistance and increase the relative effect size. There are other supporting materials available rather than electrode bare alumina, which could also stimulate the heat-flux for the sample. Grafting MIPs onto graphene fulfills both these criteria since it allows a small dimension, high surface-to-volumeratio and graphene possesses superior thermal properties[74]. While there are some examples in literature [75] [76], it is not possible to directly graft MIP layers onto graphene and therefore graphene oxide is a more viable alternative due to the presence of oxygen functionalities. Peeters et al. [77] described a method for developing a MIP-graphene oxide (GO) hybrid by employing reversible addition-fragmentation chain transfer (RAFT). The nanosized layers were capable of detecting histamine with HTM in the nanomolar regime with a similar detection limit as what was obtained with micron-sized particles. However, the drawback was that the MIP-GO hybrids still needed to be physically absorbed onto the electrodes, and directed grafting strategies from literature might further improve the detection limit [78, 79].

The main drawback in terms of sample preparation is the long preparation time and there is no direct control of the deposition of particles on the surface. Electro polymerization is an alternative that could be explored, allowing fast synthesis and monolayer coverage of the surface [20,80,81]. Control over the synthesis remains complicated however, which could be optimized by using controlled polymerization techniques [82-84]. Controlled grafting of MIPs from electrode surfaces or supports, such as silica beads, resulted in thin imprinted polymer films with a thickness in the range of 1-2 nm. The obtained structures were more homogeneous and the higher surface area lead to superior chromatographic performance compared to MIPs prepared by bulk polymerization. In the case of thermal detection, these controlled methods were not explored yet. This is particularly interesting in the case of graphene as support material since it exhibits superior thermal properties compared to the metals that are as electrodes now, such as alumina and silicon. 


\section{Thermal wave transport analysis}

In the case of HTM, the sample is kept at a fixed temperature with a constant thermal flux and stringent control is required through the feedback system. While nanomolar concentrations are measured with this technique, drawbacks include the noise originating from the temperature control and the long measurement time (15 min), which does not allow kinetic experiments. Recently, a new method was developed which focuses on a thermal wave (amplitude $=0.1^{\circ} \mathrm{C}$ ) that is transmitted through the functional interface and its output measured in the liquid (Figure 4) [33]. Thermal waves through polymers have been used in past work to study the charge distribution and transport phenomena in polymers with resolutions down to 1 micron [85]. In addition, glass transition temperatures of nano-sized polymer films were accurately determined [86]. The applications in literature for polymers are only limited and no attempt has been recorded on combining thermal waves with MIPs.

From previous research, it is known that when binding occurs onto the MIP layer, the heat-transfer resistance increases[65]. As a result, the overall response of the system to temperature fluctuations is delayed and the phase shift can be related to the amount of neurotransmitter bound on the surface of the polymer.

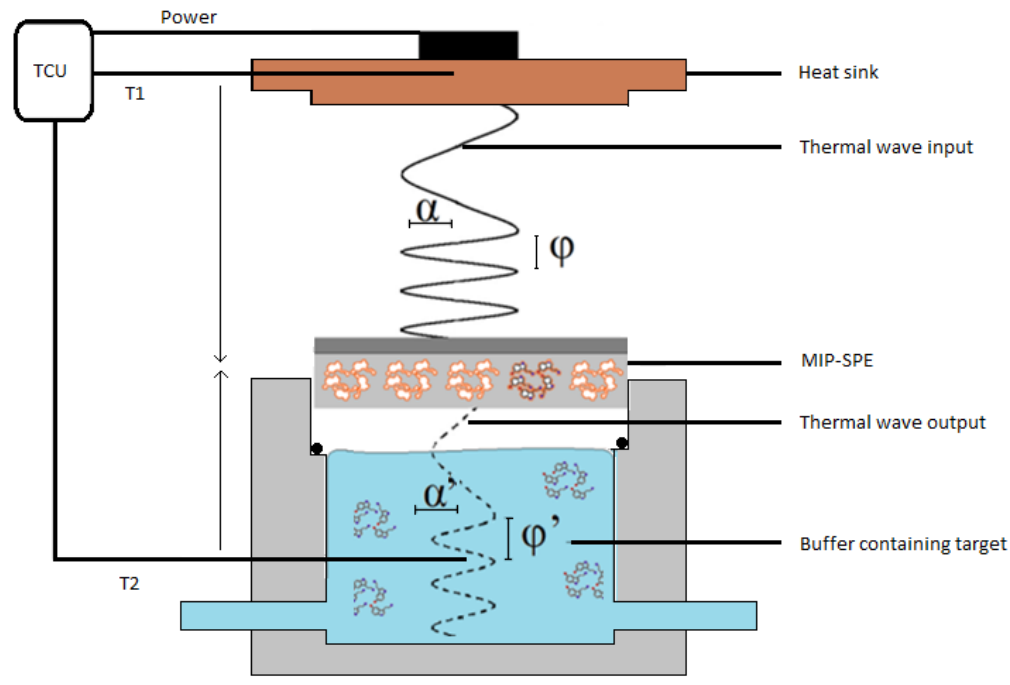

Figure 6. Schematic representation of the thermal wave analysis transport set up. A thermal wave was applied from the heat sink to the MIP-layer and the output was measured in the liquid. When targets binds to the MIP, it induces a delay in the phase $\left(\varphi \neq \varphi^{\prime}\right)$ and a reduction in amplitude

$$
\left(\alpha \neq \alpha^{\prime}\right) \text { of the signal[33]. }
$$

This technique is measured with the same equipment as for HTM and since both methods are performed simultaneously, it provides the option to directly validate results. In first proof-of-principle tests, a different approach for sample preparation was used involving the use of screen-printed 
electrodes (SPEs). SPEs were selected since they are cost-effective, highly reproducible, and suitable for incorporation into portable devices [87-89]. There are a few examples of MIP-based sensors that are combined with SPEs, but literature examples are sparse [89-91]. Peeters et al. have presented a new concept for the design of functionalized SPEs, which was based on direct mixing of the MIP particles with the bulk of the ink used to fabricate the SPEs. Various particle to ink ratios were tested, with $30 \%$ of particles vs ink giving the optimal result. Lower particle ratio, such as $5 \%$, resulted in significantly lowering the effect size. A ratio of higher than $30 \%$ was not achievable; above a certain threshold the ink loses its printability because there is not enough graphene ink present.

This is the first time MIP functionalization on SPEs is shown in a single step, allowing fast preparation and high-throughput printing of the electrodes. As proof-of-principle, MIP particles for dopamine were incorporated onto SPEs. Dopamine is a neurotransmitter that is indispensable for the efficient functioning of a variety of physiological functions and abnormalities in its concentration are associated with psychiatric disorders such as schizophrenia and depression [92, 93]. Subsequently, MIP-SPEs were mounted into the heat-transfer set up and measurements were performed with aqueous solutions that were spiked with dopamine. Detection of dopamine was proven to be specific, as no response was observed of the NIP to dopamine. To demonstrate proof-of-application of the technique, one spiked food sample was studied. In Table 4, the detection limits for SPE-MIPs are provided with three different techniques, respectively, cyclic voltammetry, HTM and TWTA. From this table, it is directly clear that TWTA has the benefit of significantly reducing measurement time and lowering detection limits in complex samples compared to HTM. To demonstrate this technique is generic, the system has to be extended to other neurotransmitters or proteins by adapting the MIP interface layer. In addition, several parameters can be varied to optimize measurements, such as the composition of the screen-printing ink, use of different SPE substrates and the thickness of the substrates.

\section{Summary}

MIP-based biosensor platforms provide a viable alternative towards to traditional ELISA assays but the potential of thermal detection technique remains relatively unexplored. Therefore, the potential of thermal methods for the detection of neurotransmitters with MIPs has been evaluated. It is focused on four detection methods, respectively: calorimetry, thermistors, the heat-transfer method, and a new technique, thermal wave transport analysis. Calorimetry allows fast and low-cost screening of template-monomer interactions and its main application is for the design and optimization of MIPs, as it enables determining heterogeneous binding sites in the synthetic receptors. The examples of MIP-based thermistors in literature are sparse and detection limits are not sufficient to measure biological samples, but it provides useful insight into the distribution of binding sites into MIP 
particles. The heat-transfer method (HTM) is an exciting and emerging technique based upon heattransfer, which can measure neurotransmitter concentrations in buffer solutions in a fast and low-cost manner. Through adapting the thermal resistance from measuring a fixed heat-transfer resistance to the application of thermal waves, the new concept thermal wave transport analysis (TWTA) was presented. Preliminary results indicate an enhanced effect size compared to HTM by reducing the noise on the signal, which provides the opportunity to measure in complex samples. In summary, thermal techniques provide a low-cost and straightforward alternative for detection of low-weight organic molecules with MIPs, which will require more study in the future to transform this platform into array formats.

\author{
Abbreviations \\ BMP - Diaminopyridine derivative \\ BSA - Bovine Serum Albumin \\ DMSO - DiMethylSulfOxide \\ ELISA - Enzyme-Linked ImmunoSorbent Assay \\ FTIR- Fourier Transformed Infrared Spectroscopy \\ GO- Graphene Oxide \\ HRP - HorseRadish Peroxidase \\ HTM - Heat-Transfer Method \\ L-BFA - L-Boc-Phenylalanine Anilide \\ MIP - Molecularly Imprinted Polymer \\ NMR - Nuclear Magnetic Resonance \\ PPV - PolyPhenyleneVinylene \\ PVC - PolyVinyl Chloride \\ RAFT - Reversible Addition-Fragmentation chain Transfer \\ $\mathrm{R}_{\mathrm{th}}$ - Thermal Resistance \\ SPE - Screen-Printed Electrode \\ TWTA - Thermal Wave Transport Analysis \\ VFU - Vinylphenyl Urea based derivative
}

\title{
Acknowledgements
}


We would like to thank the British Council Institutional Link grant (No. 172726574) and the Engineering \& Materials Research Centre (Manchester Metropolitan University) for the support of this research.

\section{References}

1. Ye L, Haupt K 2004. Molecularly imprinted polymers as antibody and receptor mimics for assays, sensors and drug discovery. Anal Bioanal Chem 378: 1887-1897. DOI 10.1007/s00216-0032450-8.

2. Haupt K, Mosbach K 2000. Molecularly Imprinted Polymers and Their Use in Biomimetic Sensors. Chem. Rev. 100: 2495-2504. DOI 10.1021/cr990099w.

3. Spivak DA 2005. Optimization, evaluation, and characterization of molecularly imprinted polymers. Adv. Drug Del. Rev. 57: 1779-1794. DOI http://dx.doi.org/10.1016/j.addr.2005.07.012.

4. Sellergren B, Allender CJ 2005. Molecularly imprinted polymers: A bridge to advanced drug delivery. Ad. Drug Del. Rev. 57: 1733-1741. DOI http://dx.doi.org/10.1016/j.addr.2005.07.010.

5. Svenson J, Nicholls IA 2001. On the thermal and chemical stability of molecularly imprinted polymers. Anal. Chimica Acta 435: 19-24. DOI http://dx.doi.org/10.1016/S0003-2670(00)01396-9.

6. Polyakov M 1931. Adsorption properties and structure of silica gel. Zhur Fhiz Kim 2: 799805.

7. Wulff G, Sarhan A 1972. Über die Anwendung von enzymanalog gebauten Polymeren zur Racemattrennung. Angewandte Chemie 84: 364-364. DOI: 10.1002/ange.19720840838.

8. Klotz IM, Royer GP, Sloniewsky A 1969. Macromolecule-small molecule interactions. Strong binding and cooperativity in a model synthetic polymer. Biochemistry 8: 4752-4756. DOI: 10.1021/bi00840a015.

9. Vlatakis G, Andersson LI, Muller R, Mosbach K 1993. Drug assay using antibody mimics made by molecular imprinting. Nature 361: 645-647. DOI:10.1038/361645a0.

10. Alexander C, Andersson HS, Andersson LI, Ansell RJ, Kirsch N, Nicholls IA, O'Mahony J, Whitcombe MJ 2006. Molecular imprinting science and technology: a survey of the literature for the years up to and including 2003. JMR 19: 106-180. DOI: 10.1002/jmr.2347.

11. Whitcombe MJ, Kirsch N, Nicholls IA 2014. Molecular imprinting science and technology: A survey of the literature for the years 2004-2011. JMR 27: 297-401. DOI: 10.1002/jmr.2347.

12. Hussain M 2015. 'Molecular Imprinting' as Multidisciplinary Material Science: Today and Tomorrow. Int. J. Adv. Mat. Res. 1: 132-154. ISSN:2381-6805.

13. Hussain M, Wackerlig J, Lieberzeit PA 2013. Biomimetic strategies for sensing biological species. Biosensors 3: 89-107. DOI: 10.3390/bios3010089.

14. Dickert FL, Lieberzeit PA, Achatz P, Palfinger C, Fassnauer M, Schmid E, Werther W, Horner G 2004. QCM array for on-line-monitoring of composting procedures. Analyst 129: 432-437. DOI: $10.1039 / \mathrm{b} 315356 \mathrm{~h}$.

15. Lieberzeit P, Rehman A, Najafi B, Dickert F 2008. Real-life application of a QCM-based enose: quantitative characterization of different plant-degradation processes. Anal Bioanal Chem 391: 2897-2903. DOI 10.1007/s00216-008-2222-6.

16. Greene NT, Shimizu KD 2005. Colorimetric molecularly imprinted polymer sensor array using dye displacement. JACS 127: 5695-5700. DOI: 10.1021/ja0468022.

17. Umpleby RJ, Baxter SC, Chen Y, Shah RN, Shimizu KD 2001. Characterization of molecularly imprinted polymers with the Langmuir-Freundlich isotherm. Anal. Chem. 73: 45844591. DOI: 10.1021/ac0105686.

18. Takeuchi T, Goto D, Shinmori H 2007. Protein profiling by protein imprinted polymer array. Analyst 132: 101-103. DOI 10.1039/B614532A. 
19. Kugimiya A, Takeuchi T 2001. Surface plasmon resonance sensor using molecularly imprinted polymer for detection of sialic acid. Biosens. Bioelectron. 16: 1059-1062.

20. Panasyuk TL, Mirsky VM, Piletsky SA, Wolfbeis OS 1999. Electropolymerized molecularly imprinted polymers as receptor layers in capacitive chemical sensors. Anal. Chem. 71: 4609-4613. DOI: $10.1021 /$ ac9903196.

21. Eppler S, Stegmaier M, Meier F, Mizaikoff B 2012. A novel extraction device for efficient clean-up of molecularly imprinted polymers. Anal. Methods 4: 2296-2299. DOI 10.1039/C2AY05821A.

22. Wackerlig J, Schirhagl R 2015. Applications of Molecularly Imprinted Polymer Nanoparticles and Their Advances toward Industrial Use: A Review. Anal Chem.. DOI 10.1021/acs.analchem.5b03804.

23. Matsui J, Akamatsu K, Hara N, Miyoshi D, Nawafune H, Tamaki K, Sugimoto N 2005. SPR sensor chip for detection of small molecules using molecularly imprinted polymer with embedded gold nanoparticles. Anal. Chem. 77: 4282-4285. DOI: 10.1021/ac050227i.

24. Jenik M, Schirhagl R, Schirk C, Hayden O, Lieberzeit P, Blaas D, Paul G, Dickert FL 2009. Sensing picornaviruses using molecular imprinting techniques on a quartz crystal microbalance. Anal. Chem. 81: 5320-5326.

25. Chianella I, Guerreiro A, Moczko E, Caygill JS, Piletska EV, De Vargas Sansalvador IMP, Whitcombe MJ, Piletsky SA 2013. Direct Replacement of Antibodies with Molecularly Imprinted Polymer Nanoparticles in ELISA-Development of a Novel Assay for Vancomycin. Anal. Chem. 85: 8462-8468. DOI 10.1021/ac402102j.

26. Lavignac N, Allender CJ, Brain KR 2004. Current status of molecularly imprinted polymers as alternatives to antibodies in sorbent assays. Anal. Chimica Acta 510: 139-145. DOI http://dx.doi.org/10.1016/j.aca.2003.12.066.

27. Piletsky SA, Piletska EV, Bossi A, Karim K, Lowe P, Turner APF 2001. Substitution of antibodies and receptors with molecularly imprinted polymers in enzyme-linked and fluorescent assays. Biosens. Bioelectron. 16: 701-707. DOI http://dx.doi.org/10.1016/S0956-5663(01)00234-2.

28. Weber A, Dettling M, Brunner H, Tovar GEM 2002. Isothermal Titration Calorimetry of Molecularly Imprinted Polymer Nanospheres. Macromolecular Rapid Communications 23: 824-828. DOI 10.1002/1521-3927.

29. Nicholls IA 1995. Thermodynamic Considerations for the Design of and Ligand Recognition by Molecularly Imprinted Polymers. Chemistry Letters 24: 1035-1036. DOI 10.1246/cl.1995.1035.

30. Yakovleva M, Bhand S, Danielsson B 2013. The enzyme thermistor-A realistic biosensor concept. A critical review. Anal. Chimica Acta 766: 1-12. DOI http://dx.doi.org/10.1016/j.aca.2012.12.004.

31. Xie B, Danielsson B, Norberg P, Winquist F, Lundström I 1992. Development of a thermal micro-biosensor fabricated on a silicon chip. Sens. Actuators B: Chem 6: 127-130. DOI http://dx.doi.org/10.1016/0925-4005(92)80043-W.

32. van Grinsven B, Vanden Bon N, Strauven H, Grieten L, Murib M, Jiménez Monroy KL, Janssens SD, Haenen K, Schöning MJ, Vermeeren V, Ameloot M, Michiels L, Thoelen R, De Ceuninck W, Wagner P 2012. Heat-Transfer Resistance at Solid-Liquid Interfaces: A Tool for the Detection of Single-Nucleotide Polymorphisms in DNA. ACS Nano 6: 2712-2721. DOI $10.1021 / \mathrm{nn} 300147 \mathrm{e}$.

33. M. Peeters BvG, C.W. Foster, T.J. Cleij, C.E. Banks 2016. Introducing Thermal Wave Transport Analysis (TWTA): A Thermal Technique for Dopamine Detection by Screen-Printed Electrodes Functionalized with Molecularly Imprinted Polymer (MIP) Particles. Molecules 21: DOI 10.3390/molecules21050552.

34. O’Mahony J, Molinelli A, Nolan K, Smyth MR, Mizaikoff B 2005. Towards the rational development of molecularly imprinted polymers: 1H NMR studies on hydrophobicity and ion-pair interactions as driving forces for selectivity. Biosens. Bioelectron. 20: 1884-1893. DOI http://dx.doi.org/10.1016/j.bios.2004.07.036. 
35. Nicholls IA, Adbo K, Andersson HS, Andersson PO, Ankarloo J, Hedin-Dahlström J, Jokela P, Karlsson JG, Olofsson L, Rosengren J 2001. Can we rationally design molecularly imprinted polymers? Anal. Chim Acta 435: 9-18.

36. Oral E, Peppas NA 2004. Dynamic studies of molecular imprinting polymerizations. Polymer 45: 6163-6173. DOI 10.1016/j.polymer.2004.06.059.

37. Biju VM, Gladis JM, Rao TP 2003. Effect of $\gamma$-irradiation of ion imprinted polymer (IIP) particles for the preconcentrative separation of dysprosium from other selected lanthanides. Talanta 60: 747-754. DOI 10.1016/S0039-9140(03)00145-0.

38. Frances HA, Susanne S, Vidyasankar S (1998) Chiral Ligand Exchange Adsorbents for Amines and Underivatized Amino Acids: 'Bait-and-Switch' Molecular ImprintingMolecular and Ionic Recognition with Imprinted Polymers American Chemical Society, pp. 109-118.

39. Ramanathan K, Danielsson B 2001. Principles and applications of thermal biosensors. Biosens. Bioelectron. 16: 417-423.

40. Zhang Y, Tadigadapa S 2004. Calorimetric biosensors with integrated microfluidic channels. Biosens. Bioelectron. 19: 1733-1743.

41. Nicholls IA 1998. Towards the rational design of molecularly imprinted polymers. JMR 11: 79-82. DOI 10.1002/(SICI)1099-1352.

42. Hsu C-Y, Lin H-Y, Thomas JL, Wu B-T, Chou T-C 2006. Incorporation of styrene enhances recognition of ribonuclease A by molecularly imprinted polymers. Biosens. Bioelectron. 22: 355-363. DOI http://dx.doi.org/10.1016/j.bios.2006.05.008.

43. Kirchner R, Seidel J, Wolf G, Wulff G 2002. Calorimetric Investigation of Chiral Recognition Processes in a Molecularly Imprinted Polymer. Journal of Inclusion Phenomena 43: 279-283. DOI 10.1023/A:1021243826862.

44. Chen W-Y, Chen C-S, Lin F-Y 2001. Molecular recognition in imprinted polymers: thermodynamic investigation of analyte binding using microcalorimetry. J. Chrom. A 923: 1-6. DOI http://dx.doi.org/10.1016/S0021-9673(01)00971-2.

45. Lin F-Y, Chen W-Y, Ruaan R-C, Huang H-M 2000. Microcalorimetric studies of interactions between proteins and hydrophobic ligands in hydrophobic interaction chromatography: effects of ligand chain length, density and the amount of bound protein. J. Chrom A. 872: 37-47. DOI http://dx.doi.org/10.1016/S0021-9673(99)01231-5.

46. Zhao D, Jia J, Yu X, Sun X 2011. Preparation and characterization of a molecularly imprinted polymer by grafting on silica supports: a selective sorbent for patulin toxin. Anal Bioanal Chem 401: 2259-2273.

47. Fish WP, Ferreira J, Sheardy RD, Snow NH, O'Brien TP 2005. Rational Design of an Imprinted Polymer: Maximizing Selectivity by Optimizing the Monomer-Template Ratio for a Cinchonidine MIP, Prior to Polymerization, Using Microcalorimetry. Journal of Liquid Chromatography \& Related Technologies 28: 1-15. DOI 10.1081/JLC-200038551.

48. Ansell RJ 2015. Characterization of the Binding Properties of Molecularly Imprinted Polymers. Adv. Biochem. Eng. Biotechnol. 150: 51-93. DOI:10.1007/10_2015_316.

49. Umpleby Ii RJ, Baxter SC, Rampey AM, Rushton GT, Chen Y, Shimizu KD 2004. Characterization of the heterogeneous binding site affinity distributions in molecularly imprinted polymers. J. Chrom. B: 804: 141-149. DOI http://dx.doi.org/10.1016/j.jchromb.2004.01.064

50. García-Calzón JA, Díaz-García ME 2007. Characterization of binding sites in molecularly imprinted polymers. Sens. Actuators B: Chem 123: 1180-1194. DOI http://dx.doi.org/10.1016/j.snb.2006.10.068.

51. Štefuca V, Voštiar I, Šefčovičová J, Katrlík J, Mastihuba V, Greifová M, Gemeiner P 2006. Development of enzyme flow calorimeter system for monitoring of microbial glycerol conversion. Applied Microbiol. Biotechn. 72: 1170-1175. DOI: 10.1007/s00253-006-0420-8.

52. Raghavan V, Ramanathan K, Sundaram P, Danielsson B 1999. An enzyme thermistor-based assay for total and free cholesterol. Clin. Chimica Acta 289: 145-158. DOI: 10.1016/S00098981(99)00174-6. 
53. Bhand SG, Soundararajan S, Surugiu-Wärnmark I, Milea JS, Dey ES, Yakovleva M, Danielsson B 2010. Fructose-selective calorimetric biosensor in flow injection analysis. Clin. Chimica Acta 668: 13-18. DOI: 10.1016/j.aca.2010.01.020.

54. Lettau K, Warsinke A, Katterle M, Danielsson B, Scheller FW 2006. A Bifunctional Molecularly Imprinted Polymer (MIP): Analysis of Binding and Catalysis by a Thermistor. Angewandte Chemie Int. Ed. 45: 6986-6990. DOI 10.1002/anie.200601796

55. Athikomrattanakul U, Promptmas C, Katterle M 2009. Synthetic receptors for neutral nitro derivatives. Tet. Letters 50: 359-362. DOI http://dx.doi.org/10.1016/j.tetlet.2008.11.015

56. Athikomrattanakul U, Gajovic-Eichelmann N, Scheller FW 2011. Thermometric Sensing of Nitrofurantoin by Noncovalently Imprinted Polymers Containing Two Complementary Functional Monomers. Anal. Chem. 83: 7704-7711. DOI 10.1021/ac201099h

57. Haupt K 2004. Molecularly Imprinted Polymers as Recognition Elements in Sensors. In: Mirsky VM (ed) Ultrathin Electrochemical Chemo- and Biosensors: Technology and Performance Springer Berlin Heidelberg, Berlin, Heidelberg, pp. 23-39.

58. Rajkumar R, Katterle M, Warsinke A, Möhwald H, Scheller FW 2008. Thermometric MIP sensor for fructosyl valine. Biosens. Bioelectron. 23: 1195-1199. DOI http://dx.doi.org/10.1016/j.bios.2007.09.015

59. Rajkumar R, Warsinke A, Möhwald H, Scheller FW, Katterle M 2008. Analysis of recognition of fructose by imprinted polymers. Talanta 76: 1119-1123. DOI: 10.1016/j.talanta/2008.05.022.

60. van Grinsven B, Vandenryt T, Duchateau S, Gaulke A, Grieten L, Thoelen R, Ingebrandt S, De Ceuninck W, Wagner P 2010. Customized impedance spectroscopy device as possible sensor platform for biosensor applications. Phys. Status Solidi A 207: 919-923. DOI 10.1002/pssa.200983305

61. van Grinsven B, Eersels K, Peeters M, Losada-Pérez P, Vandenryt T, Cleij TJ, Wagner P 2014. The Heat-Transfer Method: A Versatile Low-Cost, Label-Free, Fast, and User-Friendly Readout Platform for Biosensor Applications. ACS Applied Mat. Interf.: 27: 13309-13318. DOI $10.1021 / \mathrm{am} 503667 \mathrm{~s}$

62. Losada-Pérez P, Jiménez-Monroy KL, van Grinsven B, Leys J, Janssens SD, Peeters M, Glorieux C, Thoen J, Haenen K, De Ceuninck W, Wagner P 2014. Phase transitions in lipid vesicles detected by a complementary set of methods: heat-transfer measurements, adiabatic scanning calorimetry, and dissipation-mode quartz crystal microbalance. Phys. Status Solidi A 211: 1377-1388. DOI 10.1002/pssa.201431060.

63. Peeters M, van Grinsven B, Cleij TJ, Jiménez-Monroy KL, Cornelis P, Pérez-Ruiz E, Wackers G, Thoelen R, De Ceuninck W, Lammertyn J, Wagner P 2015. Label-free Protein Detection Based on the Heat-Transfer Method-A Case Study with the Peanut Allergen Ara h 1 and Aptamer-Based Synthetic Receptors. ACS Applied Materials \& Interfaces 7: 10316-10323. DOI 10.1021/acsami.5b00994.

64. Peeters M J-MKL, Libert C, Eurlings Y, Cuypers W, Wackers G, Duchateau S, Robaeys P, Nesládek M, van Grinsven B, Pérez-Ruiz E, Lammertyn J, Losada-Pérez P, Wagner P 2014. RealTime Monitoring of Aptamer Functionalization and Detection of Ara H1 by Electrochemical Impedance Spectroscopy and Dissipation-Mode Quartz Crystal Microbalance. Journal of Biosensors and Bioelectronics 5: 1000155.

65. Peeters M, Csipai P, Geerets B, Weustenraed A, van Grinsven B, Thoelen R, Gruber J, De Ceuninck W, Cleij TJ, Troost FJ, Wagner P 2013. Heat-transfer-based detection of 1-nicotine, histamine, and serotonin using molecularly imprinted polymers as biomimetic receptors. Anal Bioanal Chem 405: 6453-6460. DOI 10.1007/s00216-013-7024-9.

66. Eersels K, van Grinsven B, Ethirajan A, Timmermans S, Jiménez Monroy KL, Bogie JFJ, Punniyakoti S, Vandenryt T, Hendriks JJA, Cleij TJ, Daemen MJAP, Somers V, De Ceuninck W, Wagner P 2013. Selective Identification of Macrophages and Cancer Cells Based on Thermal Transport through Surface-Imprinted Polymer Layers. ACS Applied Materials \& Interfaces 5: 72587267. DOI 10.1021/am401605d 
67. Li Y, Yang H-H, You Q-H, Zhuang Z-X, Wang X-R 2006. Protein recognition via surface molecularly imprinted polymer nanowires. Anal. Chem 78: 317-320. DOI: 10.1021/ac050802i.

68. Bossi A, Bonini F, Turner A, Piletsky S 2007. Molecularly imprinted polymers for the recognition of proteins: the state of the art. Biosens. Bioelectron. 22: 1131-1137. doi:10.1016/j.bios.2006.06.023

69. Thoelen R, Vansweevelt R, Duchateau J, Horemans F, D'Haen J, Lutsen L, Vanderzande D, Ameloot M, vandeVen M, Cleij TJ, Wagner P 2008. A MIP-based impedimetric sensor for the detection of low-MW molecules. Biosens. Bioelectron. 23: 913-918. DOI http://dx.doi.org/10.1016/j.bios.2007.08.020.

70. Eersels K, van Grinsven B, Vandenryt T, Jiménez-Monroy KL, Peeters M, Somers V, Püttmann C, Stein C, Barth S, Bos GMJ, Germeraad WTV, Diliën H, Cleij TJ, Thoelen R, Ceuninck WD, Wagner P 2015. Improving the sensitivity of the heat-transfer method (HTM) for cancer cell detection with optimized sensor chips. Phys. Status Solidi A 212: 1320-1326. DOI 10.1002/pssa.201431709.

71. Eersels K, van Grinsven B, Khorshid M, Somers V, Püttmann C, Stein C, Barth S, Diliën H, Bos GMJ, Germeraad WTV, Cleij TJ, Thoelen R, De Ceuninck W, Wagner P 2015. Heat-TransferMethod-Based Cell Culture Quality Assay through Cell Detection by Surface Imprinted Polymers. Langmuir 31: 2043-2050. DOI 10.1021/la5046173.

72. Geerets B, Peeters M, Grinsven B, Bers K, de Ceuninck W, Wagner P 2013. Optimizing the Thermal Read-Out Technique for MIP-Based Biomimetic Sensors: Towards Nanomolar Detection Limits. Sensors 13: 9148. doi:10.3390/s130709148.

73. Wackers G VT, Cornelis P, Kellens E, Thoelen R, De Ceuninck W, Losada-Pérez P, van Grinsven B, Peeters M, Wagner P. 2014. Array formatting of the heat-transfer method (HTM) for the detection of small organic molecules by molecularly imprinted polymers. Sensors 14: 11016-11030. doi: $10.3390 / \mathrm{s} 140611016$.

74. Balandin AA, Ghosh S, Bao W, Calizo I, Teweldebrhan D, Miao F, Lau CN 2008 Superior thermal conductivity of single-layer graphene. Nano Letters 8: 902-907. DOI: 10.1021/n10731872.

75. Mao Y, Bao Y, Gan S, Li F, Niu L 2011. Electrochemical sensor for dopamine based on a novel graphene-molecular imprinted polymers composite recognition element. Biosens. Bioelectron. 28: 291-297. doi:10.1016/j.bios.2011.07.034.

76. Xing X, Liu S, Yu J, Lian W, Huang J 2012. Electrochemical sensor based on molecularly imprinted film at polypyrrole-sulfonated graphene/hyaluronic acid-multiwalled carbon nanotubes modified electrode for determination of tryptamine. Biosens. Bioelectron. 31: 277-283. doi: 10.1016/j.bios.2011.10.032

77. Peeters M, Kobben S, Jiménez-Monroy KL, Modesto L, Kraus M, Vandenryt T, Gaulke A, van Grinsven B, Ingebrandt S, Junkers T, Wagner P 2014/ Thermal detection of histamine with a graphene oxide based molecularly imprinted polymer platform prepared by reversible additionfragmentation chain transfer polymerization. Sensors and Actuators B: Chem. 203: 527-535. DOI http://dx.doi.org/10.1016/j.snb.2014.07.013.

78. Li Y, Li X, Dong C, Qi J, Han X 2010. A graphene oxide-based molecularly imprinted polymer platform for detecting endocrine disrupting chemicals. Carbon 48: 3427-3433. doi:10.1016/j.carbon.2010.05.038.

79. Zeng Y, Zhou Y, Kong L, Zhou T, Shi G 2013. A novel composite of SiO 2-coated graphene oxide and molecularly imprinted polymers for electrochemical sensing dopamine. Biosens. Bioelectron. 45: 25-33. doi:10.1016/j.bios.2013.01.036.

80. Blanco-López M, Lobo-Castanon M, Miranda-Ordieres A, Tunon-Blanco P 2004. Electrochemical sensors based on molecularly imprinted polymers. TrAC Trends Anal. Chem. 23: 3648. doi:10.1016/S0165-9936(04)00102-5.

81. Malitesta C, Losito I, Zambonin PG 1999. Molecularly imprinted electrosynthesized polymers: new materials for biomimetic sensors. Anal. Chem 71: 1366-1370. doi: $10.1021 / \mathrm{ac} 980674 \mathrm{~g}$. 
82. Boonpangrak S, Whitcombe MJ, Prachayasittikul V, Mosbach K, Ye L 2006. Preparation of molecularly imprinted polymers using nitroxide-mediated living radical polymerization. Biosens. Bioelectron. 22: 349-354.

83. Titirici M-M, Sellergren B 2006. Thin molecularly imprinted polymer films via reversible addition-fragmentation chain transfer polymerization. Chem. Mat. 18: 1773-1779. DOI: $10.1021 / \mathrm{cm} 052153 \mathrm{x}$.

84. Gam-Derouich S, Ngoc Nguyen M, Madani A, Maouche N, Lang P, Perruchot C, Chehimi MM 2010. Aryl diazonium salt surface chemistry and ATRP for the preparation of molecularly imprinted polymer grafts on gold substrates. Surface and Interface Analysis 42: 1050-1056. DOI: 10.1002/sia.3210.

85. Sessler GM 1997. Charge distribution and transport in polymers. IEEE Transactions on Dielectrics and Electrical Insulation 4: 614-628. DOI 10.1109/94.625648.

86. Fryer DS, Nealey PF, de Pablo JJ 2000. Thermal Probe Measurements of the Glass Transition Temperature for Ultrathin Polymer Films as a Function of Thickness. Macromolecules 33: 64396447. DOI 10.1021/ma0003349.

87. Randviir EP, Brownson DAC, Metters JP, Kadara RO, Banks CE 2014. The fabrication, characterisation and electrochemical investigation of screen-printed graphene electrodes. Phys. Chem. Chem. Phys. 16: 4598-4611. DOI 10.1039/C3CP55435J.

88. Foster CW, Metters JP, Kampouris DK, Banks CE (2014) Ultraflexible Screen-Printed Graphitic Electroanalytical Sensing Platforms. Electroanalysis 26: 262-274. DOI 10.1002/elan.201300563.

89. Kröger S, Turner APF, Mosbach K, Haupt K 1999. Imprinted Polymer-Based Sensor System for Herbicides Using Differential-Pulse Voltammetry on Screen-Printed Electrodes. Anal. Chem 71: 3698-3702. DOI 10.1021/ac9811827.

90. Croux D, Vangerven T, Broeders J, Boutsen J, Peeters M, Duchateau S, Cleij T, Deferme W, Wagner P, Thoelen R, De Ceuninck W 2013. Molecular imprinted polymer films on RFID tags: a first step towards disposable packaging sensors. Phys. Status Solidi A: 210: 938-944. DOI 10.1002/pssa.201200743.

91. Kirsch N, Hart JP, Bird DJ, Luxton RW, McCalley DV 2001. Towards the development of molecularly imprinted polymer based screen-printed sensors for metabolites of PAHs. Analyst 126: 1936-1941. DOI: 10.1039/b108008n.

92. Maouche N, Guergouri M, Gam-Derouich S, Jouini M, Nessark B, Chehimi MM (2012) Molecularly imprinted polypyrrole films: Some key parameters for electrochemical picomolar detection of dopamine. J. Electroanal. Chem 685: 21-27. DOI http://dx.doi.org/10.1016/j.jelechem.2012.08.020

93. Javitt DC, Zukin SR 1991. Recent advances in the phencyclidine model of schizophrenia. $\mathrm{Am}$ J Psychiatry 148: 1301-1308. http://dx.doi.org/10.1176/ajp.148.10.1301 


\section{Tables}

Table 1. The different properties of the detection methods ITC, thermistors, HTM, and TWTA are compared, demonstrating the weaknesses and the strength of each technique.

\begin{tabular}{|c|c|c|c|c|}
\hline & ITC & Thermistor & HTM & TWTA \\
\hline LOD & - & - & + & + \\
\hline Measurement time & ++ & + & - & + \\
\hline Costs set up & - & + & ++ & ++ \\
\hline Operating costs & ++ & ++ & ++ & ++ \\
\hline Selectivity & ++ & + & + & + \\
\hline General applicability & ++ & ++ & ++ & $?$ \\
\hline Stability & ++ & + & + & + \\
\hline Sample preparation & ++ & + & - & + \\
\hline Portability system & - & - & + & + \\
\hline
\end{tabular}

Table 2. Rebinding efficiency of MIPs and exothermal rebinding of RNase A ( $0.05 \mathrm{wt} \%$ in PBS) to various styrene containing MIPs and NIPs, as measured by ELISA and isothermal calorimetry.[42]

\begin{tabular}{|l|l|l|}
\hline Polymer compositions & Imprint factor by ELISA & Imprint factor by calorimetry \\
\hline SM-00 & 2.27 & 2.78 \\
\hline SM-10 & 8.56 & 2.75 \\
\hline SM-20 & 10.43 & 6.15 \\
\hline SM-40 & 1.53 & 4.96 \\
\hline
\end{tabular}


Table 3. The thermodynamic parameters of 2,4-D binding to MIP and NIP at different $\mathrm{pH}$ values[44]

\begin{tabular}{|c|c|c|c|c|c|c|}
\hline $\begin{array}{c}\text { Thermodynamic } \\
\text { Parameter }\end{array}$ & \multicolumn{2}{|c|}{ pH 3 } & \multicolumn{2}{c|}{ pH 6 } & \multicolumn{2}{c|}{ pH 9.5 } \\
\hline & MIP & NIP & MIP & NIP & MIP & NIP \\
\hline$\Delta \mathrm{G}_{\text {ads }}(\mathrm{kJ} / \mathrm{mole})$ & -4.35 & -2.78 & -3.11 & -5.38 & -3.27 & -6.26 \\
\hline$\Delta \mathrm{H}_{\mathrm{ads}}(\mathrm{kJ} / \mathrm{mole})$ & 3.25 & 3.25 & 0.85 & -9.52 & 8.14 & 10.25 \\
\hline$\Delta \mathrm{T} \mathrm{S}_{\text {ads }}(\mathrm{kJ} / \mathrm{mole})$ & 7.6 & 5.63 & 3.96 & -4.14 & 11.41 & 16.51 \\
\hline
\end{tabular}

Table 4. Detection limits for MIP-modified SPEs of dopamine in buffer solutions and in a food sample for cyclic voltammetry, and the thermal methods HTM, and TWTA. The sample preparation time is associated with the preparation time per sample.

\begin{tabular}{|c|c|c|c|c|}
\hline Detection method & $\begin{array}{c}\text { LOD buffer } \\
\text { solutions } \\
\text { (nM) }\end{array}$ & $\begin{array}{c}\text { LOD food sample } \\
\text { spiked with } \\
\text { dopamine (nM) }\end{array}$ & $\begin{array}{c}\text { Sample } \\
\text { preparation } \\
\text { time (min) }\end{array}$ & $\begin{array}{c}\text { Sample } \\
\text { measurement } \\
\text { time (min) }\end{array}$ \\
\hline Cyclic voltammetry & $4700 \pm 50$ & - & 1 & 2 \\
\hline $\begin{array}{c}\text { Heat-transfer } \\
\text { method (HTM) }\end{array}$ & $350 \pm 30$ & $500 \pm 50 \mathrm{nM}$ & 45 & $15-20$ \\
\hline $\begin{array}{c}\text { Thermal wave } \\
\text { transport analysis }\end{array}$ & $260 \pm 35$ & $150 \pm 40 \mathrm{nM}$ & 1 & $3-5$ \\
\hline
\end{tabular}

